\title{
Structural Determination by XAFS Spectroscopy of Non-Porphyrin Nickel and Vanadium in Maya Residuum, Hydrocracked Residuum, and Toluene-Insoluble Solid
}

\author{
J. T. Miller* and R. B. Fisher \\ Amoco Research Center, Mail Station E-1F, 150 West Warrenville Road, \\ Naperville, Illinois 60563 \\ A. M. J . van der Eerden and D. C. Koningsberger \\ Utrecht University, Department of I norganic Chemistry and Catalysis, Debye Institute, \\ P.O. Box 80083, 3508 TB, Utrecht, The Netherlands
}

Received October 21, 1998

\begin{abstract}
The local structure of non-porphyrin $\mathrm{Ni}$ and $\mathrm{V}$ in Maya residuum, hydrocracked residuum, and toluene-insoluble solid were determined by XAFS spectroscopy. In residuum, the first coordination shell of non-porphyrin $\mathrm{V}$ is similar to that for vanadyl tetraphenylporphyrin with four $\mathrm{N}$ at a distance of $2.08 \AA$ and one $\mathrm{O}$ at $1.67 \AA$. Similarly, the first coordination shell of $\mathrm{Ni}$ non-porphyrin is similar to that in nickle tetraphenylporphyrin, i.e., four $\mathrm{N}$ at a distance of 1.90 $\AA$. The $\mathrm{Ni}$ and $\mathrm{V}$ coordination geometries are remarkably stable toward thermal cracking, catalytic hydrogen, and $\mathrm{H}_{2} \mathrm{~S}$. After hydrocracking to about $60 \%$ conversion of the residuum, the local coordination of $\mathrm{Ni}$ and $\mathrm{V}$ in the hydrocracked residuum is little changed. During hydrocracking, approximately $1 \%$ of the residuum is converted to toluene-insoluble solid, which contains high levels of $\mathrm{Ni}$ and $\mathrm{V}$. Approximately $10 \%$ of the $\mathrm{Ni}$ and $\mathrm{V}$ in the solid is still present in a porphyrintype coordination geometry, while the remaining $\mathrm{Ni}$ and $\mathrm{V}$ has an octahedral coordination. In the latter, the $\mathrm{V}$ coordination contained one $\mathrm{O}$ at $1.64 \AA$, four $\mathrm{N}$ at $2.14 \AA$, and one $\mathrm{N}$ (or $\mathrm{O}$ ) at $1.96 \AA$, and the $\mathrm{Ni}$ coordination contained six $\mathrm{N}$ at $2.09 \AA$. Ni or $\mathrm{V}$ sulfides are not formed in the toluene-insoluble solid.
\end{abstract}

\section{Introduction}

Nickel and vanadium are the most abundant trace metals in petroleum and are present in amounts from about 10 to about 2000 ppm with $\mathrm{V}$, generally, in higher concentration than $\mathrm{Ni}^{1}{ }^{1}$ Typically, metal-containing compounds are high boiling $\left(>500^{\circ} \mathrm{C}\right)$ and entrained in the distillation bottoms (residuum) of crude. Additionally, the polar and aromatic nature of the metal complexes concentrates them in the asphaltene fraction of the residuum. The asphaltene fraction is that portion of the residuum which is precipitated with an excess of paraffin solvent, e.g., n-heptane. ${ }^{2}$ Asphaltenes are highly aromatic and contain more sulfur, nitrogen, and oxygen heteroatoms than the paraffin-soluble or maltene fraction of residuum. ${ }^{3}$ Generally, the higher the aromaticity and heteroatom content of the crude, the higher the level of metals in the asphaltene. Both nickel and vanadium occur in petroleum in two forms, porphyrinic and non-porphyrinic. ${ }^{1,4}$ The porphyrin fraction is identified by the presence of an ultraviolet-visible (UV-vis) absorption at about $410 \mathrm{~nm}$ (Soret band) with a weaker

* To whom correspondence should be addressed.

(1) Pearson, C. D.; Green, J . B. Fuel 1989, 68, 465.

(2) Speight, J . G.; Long R. B.; Trowbridge T. D. Fuel 1984, 63, 616.

(3) Speight, J. G. The Chemistry and Technology of Petroleum; Marcel Dekker: New York, 1991; Vol. 44, p 401.

(4) Triebs, A. Ann. Chem. 1934, 509, 103. absorption around $570 \mathrm{~nm} .^{5-7}$ Because porphyrins are readily extracted from residuum and have been used by geochemists as biomarkers to identify the geologic age of fossil fuels, numerous $\mathrm{Ni}$ and $\mathrm{V}$ porphyrin structures have been identified. ${ }^{8-10}$ By mass spectroscopic analysis, two major, homologous series of petroleum porphyrins have been identified which differ only by the substituents on the porphyrin ring. ${ }^{11}$ Because of their structural similarity, petroleum porphyrins are beli eved to have formed from chlorophyll. 4,7,12 Although

(5) Rankel, L. A. Prepr.-Am. Chem. Soc., Div. Pet. Chem. 1981, 26 (3), 689.

(6) Galiasso, R.; Garcia, J .; Caprioli, L.; Pazos, J . M.; Soto, A. Prepr.Am. Chem. Soc., Div. Pet. Chem. 1985, 30 (1), 50.

(7) Reynolds, J . G.; Biggs, W. R. Prepr.-Am. Chem. Soc., Div. Pet. Chem. 1985, 30 (4), 679.

(8) Branthaver, J . F.; Filby, R. H. Metal Complexes in Fossil Fuels: Geochemistry, Characterization, and Processing; ACS Symposium Series 344; American Chemical Society: Washington, DC, 1987; p 84.

(9) Chicarelli, M. I.; Kaur, S.; Maxwell, J . R. Metal Complexes in

Fossil Fuels: Geochemistry, Characterization, and Processing; ACS Symposium Series 344; American Chemical Society: Washington, DC, 1987; p 41

(10) Quirke, M. M. E. Metal Complexes in Fossil Fuels: Geochemistry, Characterization, and Processing; ACS Symposium Series 344; American Chemical Society: Washington, DC, 1987; p 308.

(11) Baker, E. W.; Yen, T. F.; Dickie, J . P.; Rhodes, R. E.; Clark, L. F. J . Am. Chem. Soc. 1967, 89, 3631.

(12) Filby, R. H.; van Berkel, G. J. Metal Complexes in Fossil Fuels: Geochemistry, Characterization, and Processing; ACS Symposium Series 344; American Chemical Society: Washington, DC, 1987; p 2. 
the porphyrinic compounds have been widely studied, the majority of the $\mathrm{Ni}$ and $\mathrm{V}$ occurs in non-porphyrin structures. ${ }^{1}$ Because of the difficulty in separation of non-porphyrins from the asphaltene hydrocarbons, little is known about their structure. Early ESR studies established that all of the vanadium in residuum was in the +4 oxidation state. ${ }^{13}$ In addition, the nonporphyrin $\mathrm{V}$ coordination sphere was thought to contain various combinations of sulfur, oxygen, and nitrogen ligands which were dependent on the origin of the crude. ${ }^{14-16}$ However, EXAFS and XANES of residuum indicate that the local coordination of porphyrin and non-porphyrin $\mathrm{V}$ are not significantly different, i.e., the vanadyl ion is coordinated to four $\mathrm{N}$ ligands in a squareplanar geometry. ${ }^{17-19}$ Because of its lower concentration in residuum, the local structure of non-porphyrin $\mathrm{Ni}$ has not been determined.

The objective of this study is to determine the local structure (number, type of neighbors, and bond distances) of non-porphyrin $\mathrm{Ni}$ (and $\mathrm{V}$ ) in Maya residuum. In addition, the residuum has been hydrocracked to produce lower molecular weight hydrocarbons. The local structure of $\mathrm{Ni}$ and $\mathrm{V}$ in the (unconverted) hydrocracked residuum and toluene-insoluble solid has also been determined. The results indicate that the local coordination in non-porphyrin $\mathrm{Ni}$ is similar to that in $\mathrm{Ni}$ porphyrins. In addition, the coordination geometries of $\mathrm{Ni}$ and $\mathrm{V}$ in the hydrocracked residuum are little changed from that in the residuum. Finally, approximately $10 \%$ of the $\mathrm{Ni}$ and $\mathrm{V}$ in the toluene-insoluble solid is present in a porphyrin-type coordination, while the remaining $\mathrm{Ni}$ and $\mathrm{V}$ has an octahedral coordination.

\section{Experimental Section}

Fractionation of Mayan Asphaltene. Maya residuum was obtained by vacuum distillation of Maya crude oil. The asphaltene was isolated by addition of a 40:1 excess of n-heptane to the Maya residuum at $25^{\circ} \mathrm{C} .{ }^{2}$ The suspension was stirred overnight and filtered. The precipitate was dissolved in a minimum of toluene and reprecipitated with a 40:1 excess of $n$-heptane. The preci pitate was filtered, washed with $\mathrm{n}$-heptane, and vacuum-dried at $100^{\circ} \mathrm{C}$. The yield of asphaltene was $27 \%$ of the residuum, and the elemental analysis is given in Table 1 . The asphaltene was separated into two fractions by Soxhlet extraction with $n$-heptane for 7 days. The elemental analysis and other bulk characterizations for the asphal tene fractions are also given in Table $1 .^{20}$

Residuum Hydrocracking. Residuum hydrocracking was conducted in a stirred, 300-cc autoclave (from Autoclave Engineers). Approximately $40 \mathrm{~g}$ of Maya residuum was combined with enough soluble Mo catalyst, Moly Naphthanate (Shepard Chemical Co.), to provide 500 ppm (0.05 wt \%) Mo in the reactor. The reactor was sealed, purged with hydrogen,

(13) Saraceno, A. J .; Fanale, D. T.; Coggeshall, N. D. Anal. Chem. 1961, 33, 500.

(14) Tynan, E. C.; Yen, T. F. Fuel 1969, 48, 191

(15) Dickson, F. E.; Petrakis, L. Anal. Chem. 1974, 46, 1129

(16) Reynolds, J . G.; Gallegos, E. J .; Fish, R. H.; Komlenic, J . Energy Fuels 1987, 1, 36 .

(17) Goulon, J .; Retournard, A.; Friant, P.; Goulon-Ginet, C.; Berthe, C.; Muller, J .-F.; Poncet, J .-L.; Guilard, R.; Escalier, J .-C.; Neff, B. J . Chem. Soc., Dalton Trans. 1984, 1095.

(18) Goulon, J .; Esselin, C.; Friant, P.; Berthe, C.; Muller, J .-F .; Poncet, J .-L.; Guilard, R.; Escalier, J .-C.; Neff, B. Collect. Collog. Semin. (Inst. Fr. Pet.) 1984, 40, 153.

(19) Zhang, G.; Bouduszynski, M. M. Proc. Int. Conf. Refin. Petrochem. Process 1991, 2, 821.

(20) Miller, J . T.; Fisher, R. B.; Thiyagarajan, P.; Winans, R. E.; Hunt, J. E. Energy Fuels 1998, 12, 1290.
Table 1. Elemental Analysis and Physical Characterization of Mayan Asphaltene

\begin{tabular}{lccc}
\hline \multicolumn{1}{c}{ analysis } & $\begin{array}{c}\text { residuum } \\
\text { asphaltene }\end{array}$ & $\begin{array}{c}\text { noncolloidal } \\
\text { asphaltene }\end{array}$ & $\begin{array}{c}\text { colloidal } \\
\text { asphaltene }\end{array}$ \\
\hline wt \% in asphaltene & & 20 & 80 \\
elemental analysis (wt \%) & & & \\
$\quad$ carbon & 82.9 & 83.7 & 82.5 \\
$\quad$ hydrogen & 7.7 & 8.8 & 7.3 \\
sulfur & 7.1 & 5.8 & 7.7 \\
nitrogen & 1.4 & 1.1 & 1.6 \\
oxygen & 0.9 & 0.9 & 0.9 \\
Ni (ppm) & 300 & 125 & 360 \\
V (ppm) & 1600 & 900 & 1800 \\
Ca (NMR) & 0.52 & 0.43 & 0.51 \\
mol wt (VPO) & 2650 & 900 & 5200 \\
SEC mol size (A) & 100 & 50 & 170 \\
UV-vis absorption (nm) & & & \\
Soret & 410 & 410 & trace \\
weak & 575 & 575 & trace
\end{tabular}

Table 2. Elemental Analysis and Physical Characterization of Mayan Hydrocracked Asphaltene (57\% Thermal Conversion)

\begin{tabular}{lccc}
\hline \multicolumn{1}{c}{ analysis } & $\begin{array}{c}\text { hydrocracked } \\
\text { asphaltene }\end{array}$ & $\begin{array}{c}\text { noncolloidal } \\
\text { hydrocracked } \\
\text { asphaltene }\end{array}$ & $\begin{array}{c}\text { colloidal } \\
\text { hydrocracked } \\
\text { asphaltene }\end{array}$ \\
\hline $\begin{array}{c}\text { wt \% in asphaltene } \\
\text { elemental analysis (\%) }\end{array}$ & & 29 & 71 \\
carbon & 85.3 & 85.5 & 85.8 \\
hydrogen & 6.3 & 6.7 & 6.1 \\
sulfur & 5.2 & 5.0 & 5.0 \\
nitrogen & 2.0 & 1.8 & 1.9 \\
oxygen & 1.2 & 1.1 & 1.2 \\
Ni (ppm) & 350 & 120 & 440 \\
V (ppm) & 1050 & 470 & 1300 \\
Ca (NMR) & 0.73 & 0.70 & 0.70 \\
mol wt (VPO) & 1100 & 650 & 2950 \\
UV-vis absorption (nm) & nd & 405 & none \\
Soret & nd & 466 & none \\
weak & & &
\end{tabular}

and then pressurized with hydrogen to 150 bar at $425{ }^{\circ} \mathrm{C}$ (heated to reaction temperature in approximately $10 \mathrm{~min}$ ). The residuum and hydrogen were vigorously stirred at $400 \mathrm{rpm}$ and maintained at the reaction temperature for $1 \mathrm{~h}$ giving a conversion (residuum boiling above $537^{\circ} \mathrm{C}$ to products boiling bel ow $537{ }^{\circ} \mathrm{C}$ ) of $57 \%$ determined by simulated distillation. The contents of the reactor (products, unconverted residuum, and solid) were Soxhlet extracted with toluene to yield a tolueneinsoluble (TI) solid, $1.1 \%$ based on residuum feed. The hydrocracked residuum was then distilled from the lower boiling products. The hydrocracked asphal tene was precipitated with excess $\mathrm{n}$-heptane and separated into two fractions by Soxhlet extraction with $\mathrm{n}$-heptane as above. The elemental analysis of the hydrocracked asphaltene and fractions are given in Table $2 .^{20}$

The TI solid was further separated by Soxhlet extraction with chlorobenzene for 7 days. The yield of chlorobenzenesoluble (CS) solid was $30 \%$, and the yiel d of the insoluble $(\mathrm{CI})$ solid was $70 \%$. The elemental analysis, $\mathrm{Ni}$ and $\mathrm{V}$ content, and percentage of aromatic carbon in the $\mathrm{TI}$ fractions are given in Table 3.

EXAFS. Data Collection: V K Edge The EXAFS measure ments were made at the Synchrotron Radiation Source in Daresbury, U.K., beamline 8.1, using a Si(111) double-crystal monochromator. The storage ring was operated with an electron energy of $2 \mathrm{GeV}$ and a current between 200 and 300 $\mathrm{mA}$. Samples were pressed into self-supporting wafers, and the measurements were done in the fluorescence mode at the V K edge ( $5465 \mathrm{eV})$. The monochromator was detuned by $50 \%$ in order to avoid higher harmonics in the X-ray beam. The data were collected at ambient temperature in a k-scan mode with a $5 \mathrm{~s}$ data acquisition at $15 \mathrm{k}$. 
Table 3. Elemental Analysis and Physical Characterizaions of Toluene-Insoluble Solids (57\% Thermal Conversion)

\begin{tabular}{lccc}
\hline & $\mathrm{TI}$ & $\mathrm{CS}$ & $\mathrm{Cl}$ \\
\hline wt \% & & 30 & 70 \\
elemental analysis (\%) & & & \\
$\quad$ carbon & 83.2 & 86.7 & 82.0 \\
$\quad$ hydrogen & 4.2 & 4.8 & 3.9 \\
sulfur & 5.9 & 4.9 & 6.1 \\
nitrogen & 2.3 & 2.3 & 2.3 \\
Ni (ppm) & 3000 & 800 & 3150 \\
V (ppm) & 23700 & 2400 & 28700 \\
$\mathrm{C}_{\mathrm{a}}$ (NMR) & 0.87 & 0.86 & 0.87
\end{tabular}

$\mathrm{Ni} \mathrm{K} \mathrm{Edge.} \mathrm{The} \mathrm{EXAFS} \mathrm{measurements} \mathrm{were} \mathrm{made} \mathrm{at} \mathrm{the}$ European Synchrotron Radiation Facility in Grenoble, F rance, beamline BM 29, using a $\mathrm{Si}^{311}$ double-crystal monochromator. The storage ring was operated with an electron energy of 6 $\mathrm{GeV}$ and a current between 40 and $70 \mathrm{~mA}$. Samples were sealed in Kapton tape, placed between two photodiode detectors, in order to increase the solid angle, and measured in the fluorescence mode at the $\mathrm{Ni} \mathrm{K}$ edge $(8333 \mathrm{eV})$. The monochromator was detuned by $50 \%$ in order to avoid higher harmonics in the X-ray beam. Data acquisition in the EXAFS region was $3 \mathrm{~s}$.

Data Reduction. The data were analyzed with the XDAP data analysis software. Standard procedures were used to extract the EXAFS data from the measured absorption spectra. The preedge background was approximated by a modified Victoreen curve. ${ }^{21}$ Normalization was done by dividing the height of the absorption edge, and the background was subtracted using cubic spline routines. 22 Multiple shell fitting of the EXAFS data was done in R-space. The difference file technique was applied, together with phase-corrected F ourier transforms, to resolve the different contributions. The quality of the fit was determined by the difference between the absolute and imaginary part of the Fourier transform of the experimental data with that of the model Fourier transform. The R-space fit of the $\mathrm{Ni}$ samples were performed with a $\mathrm{k}^{1}$ weighted Fourier transform using a k-fit range of 2.5-9.0 and an $r$-fit range of $1.0-1.8 \AA$ with the exception of the chlorobenzene-insoluble TI solid wherethe $r$-fit range was 1.0$2.5 \AA$. The $R$-space fit of the $V$ samples were performed with a $\mathrm{k}^{1}$-weighted Fourier transform using a k-fit range of 3.8$9.0 \AA^{-1}$ and an r-fit range of $1.0-2.0 \AA$.

Reference Compounds. The phase shift and backscattering amplitude for the $\mathrm{V}-\mathrm{O}$ (and $\mathrm{V}-\mathrm{N}$ ) backscattering pair were obtained from the EXAFS data $\left(\mathrm{k}^{3}: \Delta \mathrm{k}=3.5-12.2 \AA^{-1}, \Delta \mathrm{r}=\right.$ 0.5-2.0 $\AA$ ) for $\mathrm{Na}_{3} \mathrm{VO}_{4}$. The literature XRD values for the firstshell $\mathrm{V}-\mathrm{O}$ coordination number and interatomic distance is 4 and $1.696 \AA$, respectively. The FEFF code (version 3.11) was used to calculate the phase shift and backscattering amplitude for the $\mathrm{Ni}-\mathrm{N}\left(\mathrm{N}=4, \mathrm{R}=2.05 \AA,\left(\sigma=0.003 \AA^{2}, \mathrm{~S}_{0}{ }^{2}=0.75\right)\right.$ adsorber-backscatter pair. The references were calibrated against 5,10,15,20-tetraphenyl-21H,23H-porphrinenickel(II) [Ni TTP] and 5,10,15,20-tetraphenyl-21H,23H-porphrinevanadium(IV) oxide [V TPP] which are commercially available (Aldrich).

\section{Results}

The elemental analysis and bulk properties of Mayan asphaltene (Table 1 ) agree with previous results. ${ }^{23}$ Approximately $20 \%$ of Mayan asphaltene is very slightly soluble in $\mathrm{n}$-heptane and can be separated by Soxhlet extraction. A detailed comparison of two fractions has

(21) Vaarkamp, M.; Dring, I.; Oldman, R. J .; Stern, E. A.; Koningsberger, D. C. Phys. Rev. B 1994, 50, 7872.

(22) Cook, J . W., J r.; Sayers, D. E. J . Appl. Phys. 1981, 52, 5024.

(23) Shaw, J . E. Fuel 1989, 68, 1218. previously been reported. ${ }^{20}$ The lower molecular weight by vapor-phase osmometry (VPO) and the smaller size by size-exclusion chromatography and small-angle neutron scattering indicate that the extracted fraction is noncolloidal in solution, while the nonextracted asphaltene forms large, colloidal aggregates with high VPO mol ecular weights. ${ }^{20}$

Approximately $10 \%$ of the residuum $\mathrm{Ni}$ and $\mathrm{V}$ is present in the noncolloidal asphaltene fraction. The UV-vis spectra of this fraction displays a Soret absorption at $410 \mathrm{~nm}$ with a smaller absorbance at $575 \mathrm{~nm}$, which are characteristic of $\mathrm{Ni}$ and $\mathrm{V}$ petroporphyrins. ${ }^{5-7}$ By contrast, the remaining $90 \%$ of the $\mathrm{Ni}$ and $\mathrm{V}$ is present in the colloidal asphaltene fraction and displays a very weak UV-vis absorbance, indicating that less than about $1 \%$ of these metals are porphyrinic.

Maya residuum was reacted at $425^{\circ} \mathrm{C}$ for $1 \mathrm{~h}$ at 150 bar of hydrogen with 0.05 wt \% sol uble M o catalyst. ${ }^{24-27}$ The conversion to lower molecular weight products, i.e., hydrocracking, was $57 \%$. Like the residuum asphaltene, approximately $30 \%$ of the hydrocracked asphaltene is very slightly soluble in $n$-heptane and was isolated by Soxhlet extraction. Although the composition of the two asphaltene fractions is similar, the VPO molecular weights indicate that the extracted fraction is noncolloidal while the remaining asphaltene is colloidal. ${ }^{20}$ Approximately $25 \%$ of the total $\mathrm{Ni}$ and $\mathrm{V}$ is present in the noncolloidal, hydrocracked asphaltene, and the presence of the Soret band at $405 \mathrm{~nm}$ and a weaker absorption at $566 \mathrm{~nm}$ in the UV-vis spectrum indicate that these metals are porphyrinic. The remaining 75\% of $\mathrm{Ni}$ and $\mathrm{V}$ is present in the colloidal, hydrocracked asphaltene; however, these do not display any UV-vis absorptions. Thus, they are non-porphyrin $\mathrm{Ni}$ and $\mathrm{V}$. For both residuum and hydrocracked asphaltene, the porphyrinic $\mathrm{Ni}$ and $\mathrm{V}$ is present in the noncolloidal asphal tene while the $\mathrm{Ni}$ and $\mathrm{V}$ in the colloidal asphaltene is non-porphyrinic.

At $60 \%$ hydrocracking conversion, approximately $1 \%$ of the residuum is converted to a solid which is no longer soluble in toluene. The elemental composition of the toluene-insoluble ( $\mathrm{TI}$ ) solid is given in Table 3. The composition of solid indicates that the hydrogen content is lower, the $\mathrm{S}$ and $\mathrm{N}$ contents are similar, and the $\mathrm{Ca}$ content is higher than the hydocracked asphaltene. In addition, the $\mathrm{Ni}$ and $\mathrm{V}$ contents of the $\mathrm{TI}$ solid are much higher than in the hydrocracked asphaltene. Although the solid was completely insoluble in toluene, approximately $30 \%$ was very slightly soluble in chlorobenzene and isolated by Soxhlet extraction. The elemental composition of the two TI fractions is also given in Table 3. Although the elemental composition of the two solids differs slightly, there is a large difference in the $\mathrm{Ni}$ and $\checkmark$ contents. Approximately $9 \%$ of the metals were present in the chlorobenze-soluble (CS) solid, while in the chlorobenzene-insoluble $(\mathrm{Cl})$ solid the $\mathrm{Ni}$ and $\mathrm{V}$ contents were very high, 0.31 and 2.87 wt \%, respectively.

Local Structure Determination of Vanadium by XAFS Spectroscopy. Figure 1 shows the raw EXAFS

(24) Bearden, R.; Aldridge, C. L. Energy Prog. 1981, 1, 44.

(25) Chen, H. H.; Montgomery, D. S.; Strausz, O. P. AOSTRA J . Res. 1988, 4, 143.

(26) Del Bianco, A.; Panariti, N.; Di Carlo, S.; Elmouchnino, J .; Fixari, B.; Le Perchec, P. Appl. Catal. A: Gen. 1993, 94, 1.

(27) Heck, R. H.; DiGuiseppi, F. T. Energy Fuels 1994, 8, 557. 

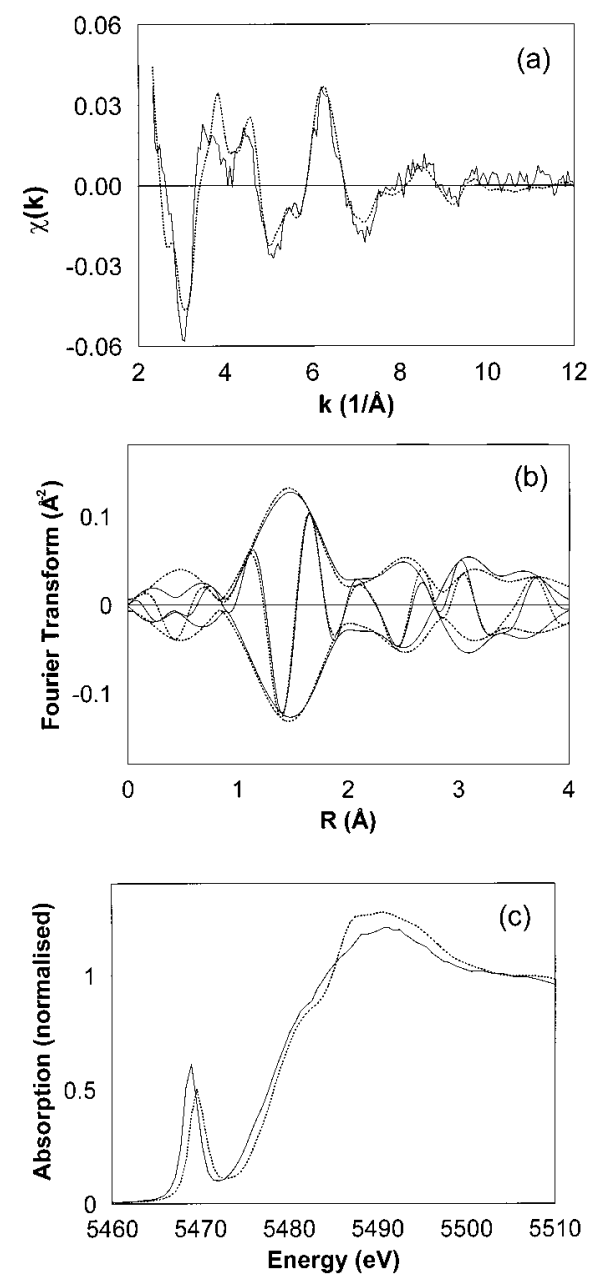

Figure 1. $V$ XAFS spectra of non-porphyrin $\mathrm{V}$ in Mayan, colloidal asphaltene (solid line) and vanadyl tetraphenylporphyrin (V TPP) reference (dotted line). (a) Raw EXAFS data. (b) Fourier transform $\left(\mathrm{k}^{1}, \Delta \mathrm{k}=2.5-10 \AA^{-1}\right)$. (c) Near edge.

data, the F ourier transforms, and the near-edge spectra of non-porphyrin $\mathrm{V}$ in Mayan colloidal asphaltene (solid line) and the vanadyl tetraphenyl porphyrin (V TPP) reference compound (dotted line). The small differences in the raw data and Fourier transforms are due to a higher noise level in the data of the non-porphyrin $\mathrm{V}$ and possibly also due to subtle changes in the higher coordination shells. The similarity of the preedge peak indicates that the coordination geometry of $\mathrm{V}$ in the colloidal asphaltene is similar to that of V TPP. The differences in the near-edge spectra (at about $5488 \mathrm{eV}$ ) are also consistent with subtle changes in the first and higher coordination shells. All spectra confirm that within the accuracy of the data, the first coordination shell of non-porphyrin $\mathrm{V}$ is similar to that in V TPP, i.e., vanadyl ion $\left(\mathrm{VO}^{+2}\right)$ coordinated by four $\mathrm{N}$ in a square planar configuration.

The results of $r$-space fitting of the V TPP using the $\mathrm{V}-\mathrm{O}$ reference (see Experimental Section) are given in Table 4. The $\mathrm{V}-\mathrm{N}$ and $\mathrm{V}-\mathrm{O}$ bond distances determined by EXAFS were 2.07 and $1.59 \AA$, respectively. These values are in good agreement with the bond distances of $2.10(\mathrm{~V}-\mathrm{N})$ and $1.62 \AA(\mathrm{V}-\mathrm{O})$ determined by $\mathrm{X}$-ray diffraction (XRD). ${ }^{28}$ Because of the similarity of the EXAFS data with that of $V$ TPP, the coordination

(28) Molinaro, F. S.; I bers, J . A. Inorg. Chem. 1976, 15, 2278. numbers were restricted to four $\mathrm{N}$ and one $\mathrm{O}$ in the model fit of non-porphyrin $\mathrm{V}$. The $\mathrm{V}-\mathrm{N}$ and $\mathrm{V}-\mathrm{O}$ bond distances determined from fitting of the EXAFS data, Table 4, are 2.08 and $1.67 \AA$, respectively. The $V-N$ distance of $2.08 \AA$ in the asphaltene is within the limits of accuracy of the data $(0.03 \AA)$, the same as that in the reference compound. The $\mathrm{V}-\mathrm{O}$ distance of $1.65 \AA$ in $\mathrm{V}$ non-porphyrin is typical of the vanadium(IV)-oxygen double bond. Although the $\mathrm{V}-\mathrm{N}$ and $\mathrm{V}-\mathrm{O}$ distances are similar to those in V TPP, a larger value in the disorder $\left(\Delta \sigma^{2}\right)$ of non-porphyrin $\mathrm{V}$ indicates that there is a greater variation in the four $\mathrm{V}-\mathrm{N}$ bond distances.

Figure 2 shows the EXAFS data, Fourier transform, and near-edge spectra of $\mathrm{V}$ in the colloidal asphaltene (sol id line) and noncolloidal asphaltene (dotted line). The majority of the $\mathrm{V}$ in the noncolloidal asphaltene is porphyrinic. The spectra are nearly identical, indicating a similar $\mathrm{V}$ coordination. The $\mathrm{V}-\mathrm{N}$ and $\mathrm{V}-\mathrm{O}$ distances for noncolloidal $V$, i.e., vanadyl petroporphyrin, are also given in Table 4 and are 2.04 and $1.65 \AA$, respectively. The EXAFS data, Fourier transforms, and near-edge spectra for $\mathrm{V}$ in hydrocracked, Mayan colloidal and noncolloidal asphaltene were al so within experimental error identical to those in the residuum. Thus, they are not shown. The results of the fits are given in Table 4. For hydrocracked non-porphyrin $\mathrm{V}$, the $\mathrm{V}-\mathrm{N}$ distance is about $2.05 \AA$ and the $\mathrm{V}-\mathrm{O}$ distance is about $1.63 \AA$. As observed for the $V$ in the residuum, the disorder in the $\mathrm{V}-\mathrm{N}$ bond distance is larger in the hydrocracked non-porphyrin $\mathrm{V}$.

During the (thermal) hydrocracking conversion, TI solid is formed, which contains about $60 \%$ of the $V$ originally present in the residuum. This solid has been fractionated based on its partial solubility in chlorobenzene. The Fourier transform of the $\mathrm{V}$ present in the chlorobenzene-soluble (CS) solid (solid line) is compared in Figure 3 with the Fourier transform of the V TPP (dotted line). As can be seen by the similarity in the first-shell ( $1 \AA<\mathrm{R}<2 \AA$ ) and the second-shell region $(2 \AA<\mathrm{R}<2.8 \AA)$, the local structures are very nearly identical. Also, the near-edge spectra (not shown) are very similar. Fitting the first-shell region with a four $\mathrm{N}$ and one $\mathrm{O}$ neighbor leads to $\mathrm{V}-\mathrm{N}$ distance of 2.17 $\AA$ and a $V-O$ distance of $1.57 \AA$. Although the local structure around the $V$ in the CS solid is similar to that in the vanadyl porphyrins, i.e., number and type of neighbors, there is a significant change in both the $\mathrm{V}-\mathrm{N}$ and $\mathrm{V}-\mathrm{O}$ coordination distances. These differences in bond distance compared to the residuum samples, however, may be due tothe low amplitude of the EXAFS signal and the high signal-to-noise ratio in the data at high k. Comparison of the Fourier transform of the raw data (solid line) and the model fit (dotted line) are shown in Figure 4.

A comparison of the EXAFS data, Fourier transform, and near-edge spectra of $\mathrm{V}$ in the CS (solid line) and $\mathrm{CI}$ solid (dotted line) is given in Figure 5. Both the EXAFS spectra and the F ourier transform indicate that the local structure of $\mathrm{V}$ in these two fractions is completely different. This is confirmed by the near-edge spectra of the $\mathrm{Cl}$ solid where there is a shift to higher energy and a lowering of the peak amplitude of the preedge peak indicative of an increase in coordination symmetry around the $\mathrm{V}$. In addition, the differences in the near- 
Table 4. V EXAFS Parameters of Model Fit

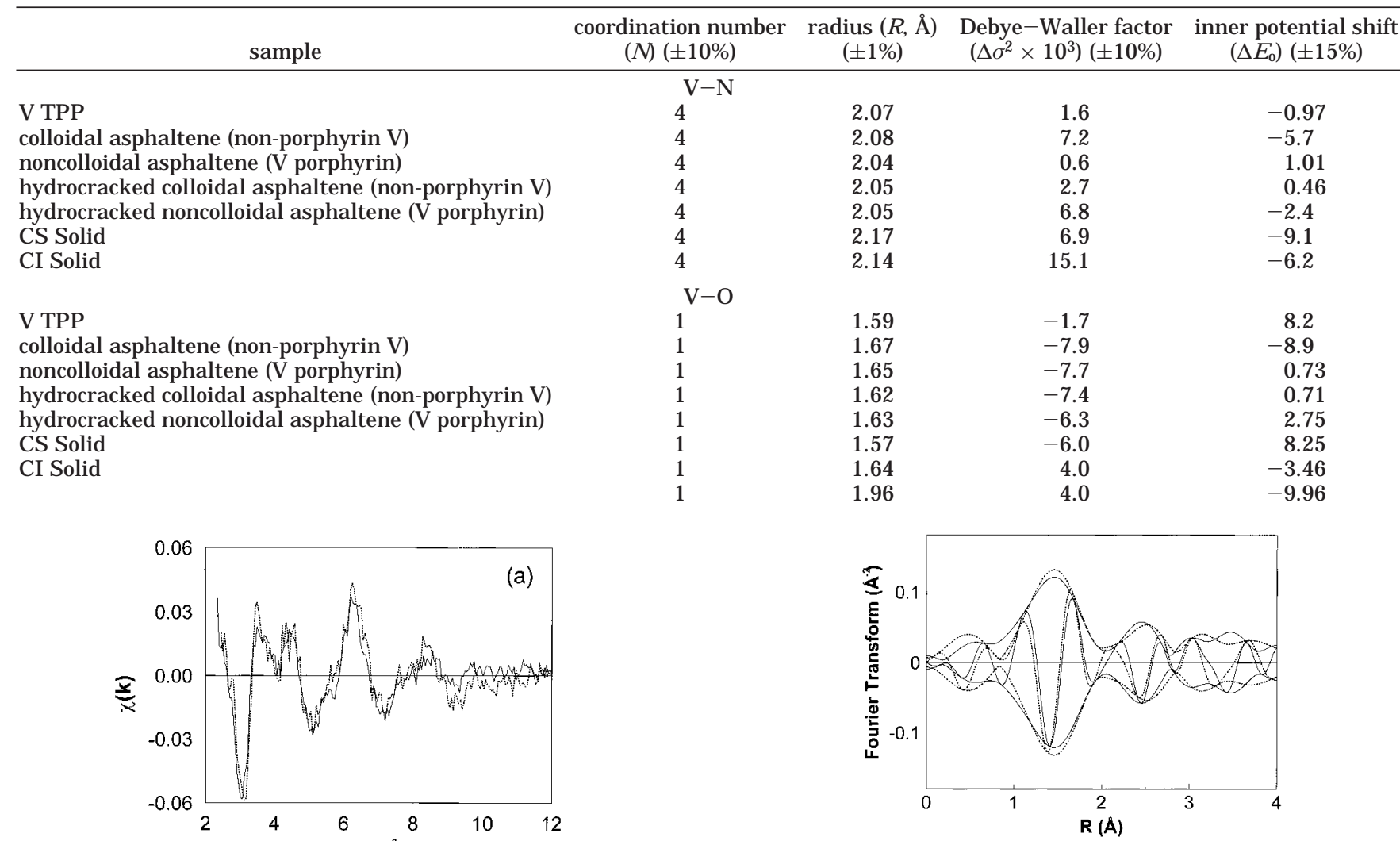

Figure 3. Fourier transform $\left(\mathrm{k}^{1}, \Delta \mathrm{k}=2.5-10 \AA^{-1}\right)$ of $\mathrm{V}$ EXAFS data of the chlorobenzene-soluble (CS) solid (solid line) and $V$ TPP reference (dotted line).
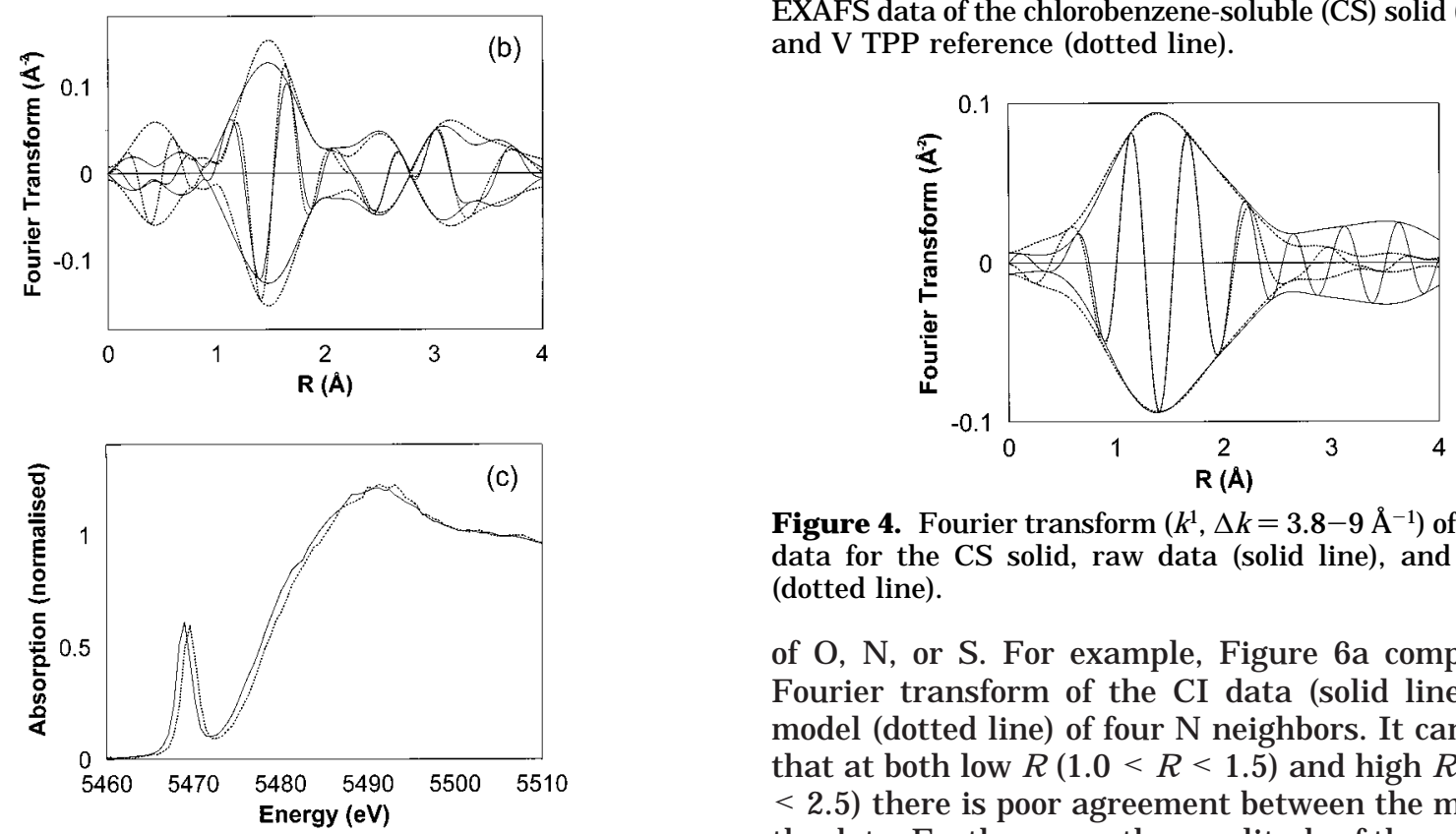

Figure 2. $V$ XAFS spectra of non-porphyrin $V$ in Mayan, colloidal asphaltene (solid line) and (porphyrinic) $\mathrm{V}$ in noncolloidal asphaltene (dotted line). (a) Raw EXAFS data. (b) Fourier transform $\left(\mathrm{k}^{1}, \Delta \mathrm{k}=2.5-10 \AA^{-1}\right)$. (c) Near edge.

edge spectra (at about $5490 \mathrm{eV}$ ) are al so consistent with significant changes in the coordination environment.

Several structural models which included coordination neighbors of $\mathrm{N}, \mathrm{O}$, and $\mathrm{S}$ were evaluated to fit the data for the $\mathrm{V}$ in the $\mathrm{Cl}$ solid. The EXAFS data could not be fit with a porphyrin-type structure in which there are either four $\mathrm{N}$ and one $\mathrm{O}$ or four $\mathrm{N}$ and one $\mathrm{S}$. Neither could the data be fit with four-coordination neighbors

Figure 4. Fourier transform $\left(\mathrm{K}^{1}, \Delta \mathrm{k}=3.8-9 \AA^{-1}\right)$ of V EXAFS data for the CS solid, raw data (solid line), and model fit (dotted line).

of $\mathrm{O}, \mathrm{N}$, or $\mathrm{S}$. For example, Figure 6a compares the Fourier transform of the $\mathrm{Cl}$ data (solid line) with a model (dotted line) of four $\mathrm{N}$ neighbors. It can be seen that at both low $\mathrm{R}(1.0<\mathrm{R}<1.5)$ and high $\mathrm{R}(1.8<\mathrm{R}$ $<2.5$ ) there is poor agreement between the model and the data. Furthermore, the amplitude of the magnitude in the Fourier transform of the model is much higher than that in the data. Addition of one $\mathrm{O}$ neighbor at low R, Figure $6 b$, i.e., the porphyrin structure type, improves the fit of the imaginary part at low $\mathrm{R}$, however, the amplitude in the fit remains unsatisfactory. In addition, there are still differences in the imaginary part and magnitude at high R. Finally, inclusion of an additional $\mathrm{O}$ (or $\mathrm{N}$ ) neighbor at high $\mathrm{R}$, Figure $6 \mathrm{c}$, results in a good fit in both the imaginary part and magnitude of the Fourier transform in all regions. The model fit suggests that the local $\mathrm{V}$ coordination in the $\mathrm{Cl}$ solid is a distorted octahedron. This coordination geometry is 

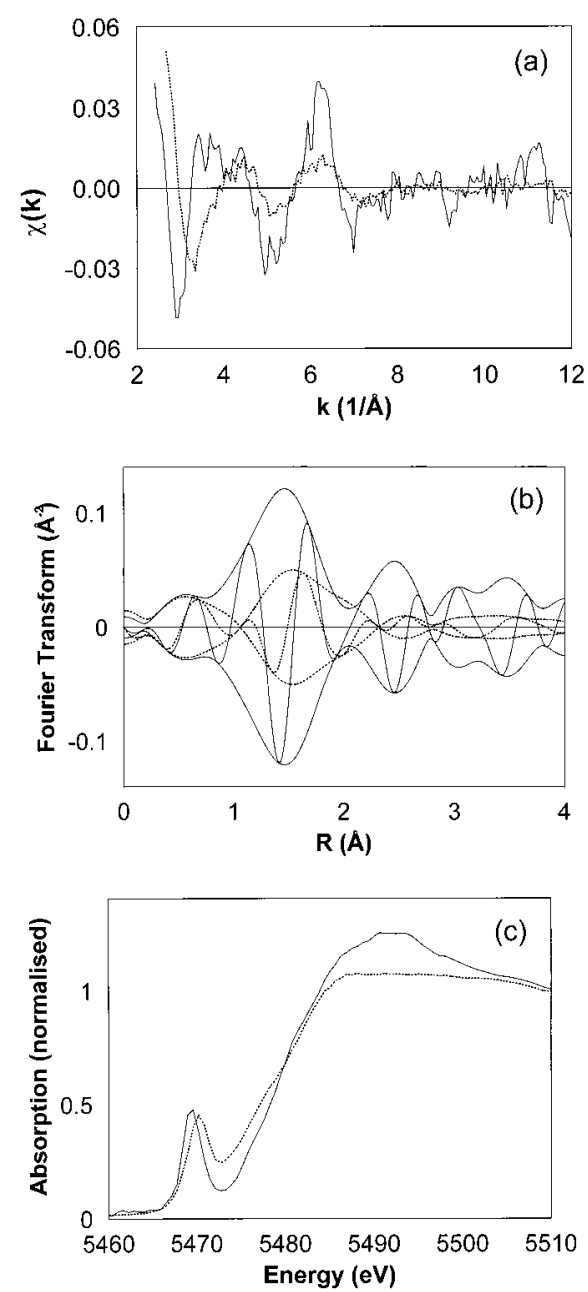

Figure 5. $V$ XAFS spectra for the CS (solid line) and chlorobenzene-insoluble $(\mathrm{Cl})$ (dotted line) solid. (a) Raw EXAFS data. (b) Fourier transform $\left(\mathrm{k}^{1}, \Delta \mathrm{k}=2.5-10 \AA^{-1}\right)$. (c) Near edge.

also consistent with the changes in the near-edge spectra, indicating an increase in symmetry compared to the square pyramid of a vanadyl porphyrin. The results from the model fit are given in Table 4 . There are four $\mathrm{N}$ neighbors at a distance of $2.14 \AA$, one $\mathrm{O}$ neighbor at $1.64 \AA$, and one $O$ neighbor at $1.96 \AA$. The $\mathrm{V}-\mathrm{N}$ distance is similar to that in the CS solid, and the $\mathrm{V}-\mathrm{O}$ distance $(1.64 \AA$ ) is similar to that in the vanadyl ion. The $\mathrm{Cl}$ solid also contains one additional $\mathrm{O}$ not present in the other samples and reference.

Local Structure Determination of Nickel by XAFS Spectroscopy. The EXAFS raw data, Fourier transform, and near-edge spectra of non-porphyrin $\mathrm{Ni}$ (solid line) in Mayan colloidal asphaltene and Ni TPP (dotted line) are shown in Figure 7. Despite the much lower signal-to-noise ratio in non-porphyrin $\mathrm{Ni}$, the similarity of the EXAFS data and near-edge spectra with that of the Ni TPP are apparent, and the differences are due primarily to noise in the data of the nonporphyrin $\mathrm{Ni}$. The EXAFS data of $\mathrm{Ni}$ TPP were fit using a $\mathrm{Ni}-\mathrm{O}$ reference (see Experimental Section). The $\mathrm{Ni}-\mathrm{N}$ coordination distance was $1.93 \AA$, in agreement with $1.96 \AA$ determined by XRD. ${ }^{29}$ The EXAFS data of nonporphyrin $\mathrm{Ni}$ could be fit with a coordination of four $\mathrm{N}$

(29) Collins, D. M.; Hoard, J . L. J . Am. Chem. Soc. 1970, 92, 3761.
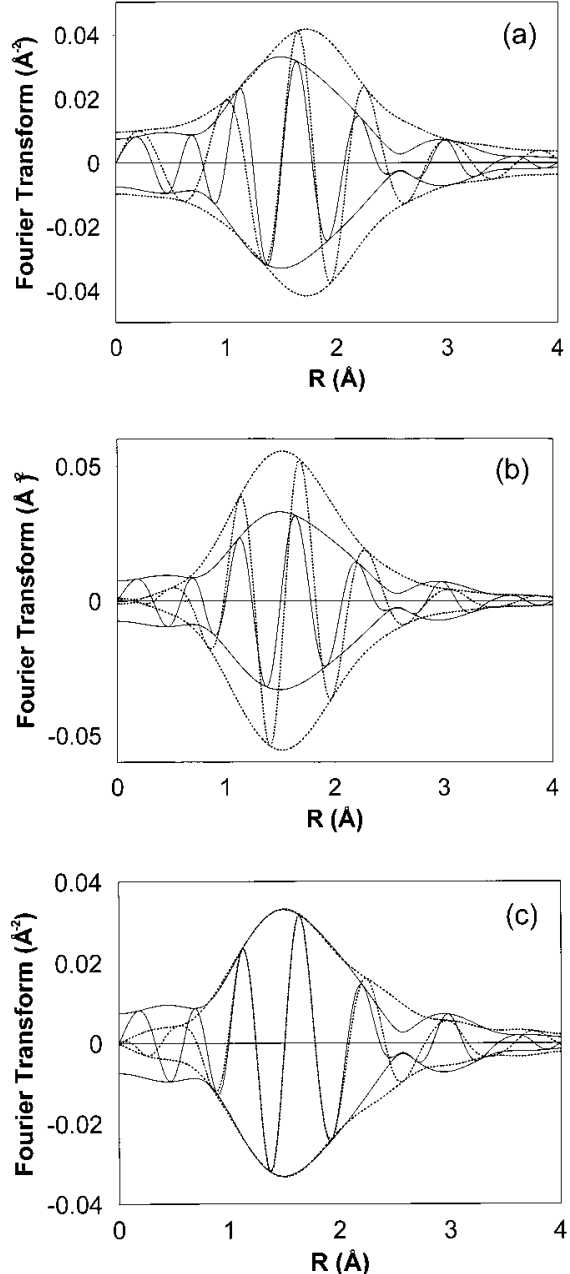

Figure 6. F ourier transform $\left(k^{1}, \Delta k=3.8-9 \AA^{-1}\right)$ of $V$ EXAFS data for the $\mathrm{Cl}$ solid, raw data (solid line), and model fit (dotted line). (a) Fit of four $\mathrm{N}$ neighbors. (b) Fit of four $\mathrm{N}$ neighbors and one $\mathrm{O}$. (c) Fit of four $\mathrm{N}$ neighbors and two $\mathrm{O}$ neighbors.

at a distance of $1.90 \AA$ and within experimental error is the same as that in Ni TTP. The level of $\mathrm{Ni}$ in the noncolloidal asphaltene was too low to detect, even in fluorescence.The EXAFS data, F ourier transforms, and near-edge spectra (not shown) of non-porphyrin $\mathrm{Ni}$ in the hydrocracked, colloidal asphaltene were similar to that in non-porphyrin $\mathrm{Ni}$ (in residuum) shown in Figure 7. The results of the fits are given in Table 5, and the $\mathrm{Ni}-\mathrm{N}$ distance is $1.86 \AA$. Similarly, within the uncertainty of the noise, the XAFS spectra of the Ni petroporphyrins in the noncolloidal, hydrocracked asphaltene were also identical to that of the non-porphyrin $\mathrm{Ni}$ and $\mathrm{Ni}$ TTP. The $\mathrm{Ni}-\mathrm{N}$ coordination distance (Table 5) was $1.94 \AA$.

Comparison of the F ourier transform of $\mathrm{Ni}$ in the $\mathrm{CS}$ solid (solid line) with Ni TPP (dotted line) is given in Figure 8. The similarity of the two spectra indicate that the local $\mathrm{Ni}$ structure is the same, i.e., four $\mathrm{N}$ in a square planar coordination. The results of the fit, Table 5, indicate that the $\mathrm{Ni}-\mathrm{N}$ distance is $1.85 \AA$. A comparison of the F ourier transform of the raw data (solid line) and the model fit (dotted line) for the CS solid is shown in Figure 9.

A comparison of the EXAFS data, F ourier transform, and near-edge spectra of $\mathrm{Ni}$ in the CS (solid line) and $\mathrm{Cl}$ (dotted line) solid is given in Figure 10. Both the 

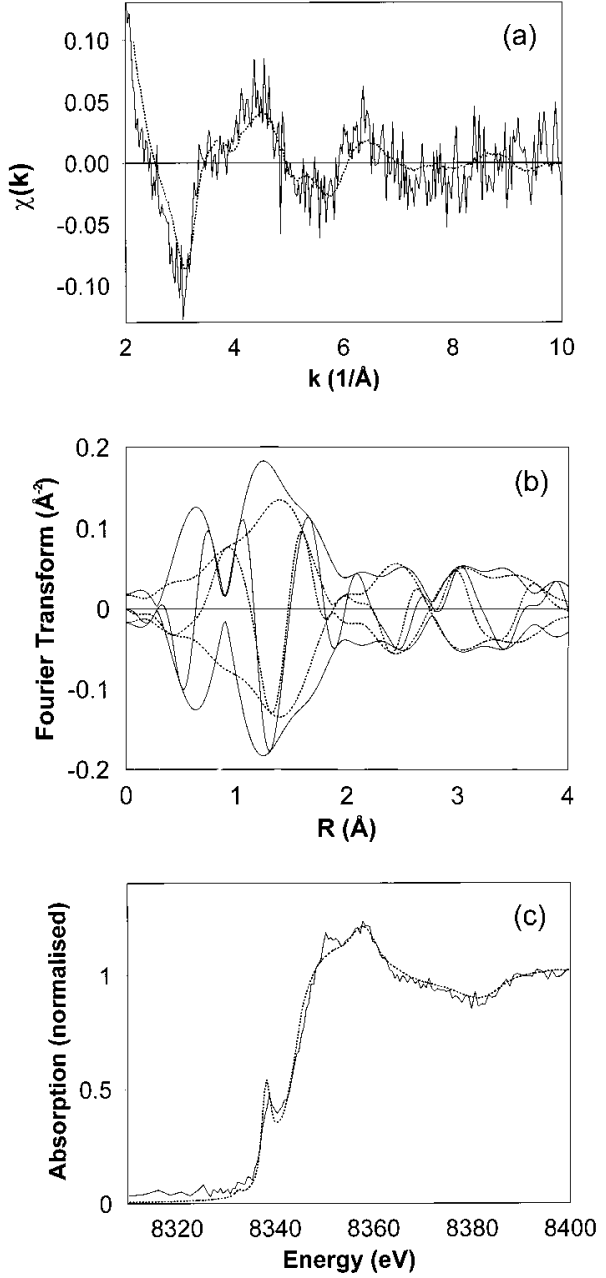

Figure 7. Ni XAFS spectra for non-porphyrin $\mathrm{Ni}$ in Mayan colloidal asphaltene (solid line) and nickel tetraphenylporphyrin (Ni TPP) reference (dotted line). (a) Raw EXAFS data. (b) Fourier transform $\left(\mathrm{k}^{1}, \Delta \mathrm{k}=2.5-10 \AA^{-1}\right)$. (c) Near edge.

EXAFS and near-edge spectra indicate that the local structure of $\mathrm{Ni}$ is very different in these two fractions. The shift in the imaginary part from about $1<\mathrm{R}<1.8$ to higher $\mathrm{R}$ values indicates that the $\mathrm{Ni}-\mathrm{N}$ distance is longer in the $\mathrm{Cl}$ solid. Also, the low intensity of the preedge peak in the near-edge spectra is consistent with octahedral coordination. Several structural models which included coordinations of $\mathrm{N}, \mathrm{O}$, and $\mathrm{S}$ were evaluated in the fit of the Ni EXAFS data. A good fit was obtained by including two additional $\mathrm{N}$ (or $\mathrm{O}$ ) neighbors in the coordination shell to the four $\mathrm{N}$ of the porphyrin ring. The $\mathrm{Ni}-\mathrm{N}$ distance (six neighbors) in the $\mathrm{Cl}$ solid was 2.09 $\AA$. Comparison of the Fourier transform of the raw data (solid line) and the model fit (dotted line) for the $\mathrm{Cl}$ solid are shown in Figure 11.

\section{Discussion}

Although both Mayan asphaltene fractions contain $\mathrm{Ni}$ and $\mathrm{V}$, about $90 \%$ of the $\mathrm{Ni}$ and $\mathrm{V}$ is present in the colloidal asphaltene and the UV-vis absorption spectrum indicates these metals contain few petroporphyrins. Thus, they are non-porphyrin $\mathrm{Ni}$ and $\mathrm{V}$. These results agree with previous studies which indicate that non-porphyrin $\mathrm{Ni}$ and $\mathrm{V}$ are present in large asphaltene structures with high (VPO) molecular weights. ${ }^{30}$
The noncolloidal asphaltene, by contrast, contains approximately $10 \%$ of the $\mathrm{Ni}$ and $\mathrm{V}$, and the UV-vis spectrum indicates the presence of porphyrins. Maya residuum has previously been reported to contain $13 \%$ porphyrinic $\mathrm{Ni}$ and $\mathrm{V} .{ }^{30}$ In addition, by size-exclusion chromatography using ion-sensitive detectors, it was concluded that the $\mathrm{Ni}$ and $\mathrm{V}$ porphyrins have a molecular size characteristic of maltenes. ${ }^{30} \mathrm{~F}$ urthermore, the $\mathrm{Ni}$ and $\mathrm{V}$ petroporphyrins were precipitated al ong with the asphaltene and were very slightly soluble in paraffin solvents. ${ }^{31}$ The noncolloidal asphaltene, therefore, contains predominantly $\mathrm{Ni}$ and $\mathrm{V}$ petroporphyrins.

As observed for the residuum asphaltenes, UV-vis absorption spectra indicate that porphyrinic $\mathrm{Ni}$ and $\mathrm{V}$ are present in the noncolloidal, hydrocracked asphaltene fraction and non-porphyrin $\mathrm{Ni}$ and $\mathrm{V}$ is present in the colloidal, hydrocracked asphaltene fraction. The local coordination geometry of non-porphyrinic $\mathrm{V}$ in residua has been previously determined by ESR and XAFS spectroscopies. On the basis of the shifts in the Landré factor $\left(\mathrm{g}_{\mathrm{o}}\right)$, it was concluded that asphaltenes contained vanadyl ions, i.e., $\mathrm{V}=\mathrm{O}^{+2}$, bonded to $\mathrm{N}, \mathrm{O}$, and $\mathrm{S}$ ligands. ${ }^{14-16}$ The specific $V$ coordination geometry was dependent on the geological history of that crude. ${ }^{16}$ From high-resolution ESR measurements, i.e., obtained at higher magnetic field strength, however, it was concluded that the $\mathrm{V}$ coordination could not be determined from the go value as previously reported, although the $V$ coordination was sensitive to the value of the hyperfine coupling constant. Quantitative analysis of the high-resolution ESR data, however, was unable to differentiate between the vanadyl ion with squareplanar ligand coordination containing $\mathrm{S}, \mathrm{N}$, or $\mathrm{O} .32$ Therefore, ESR cannot be used to identify the local structure of $\mathrm{V}$ in asphaltenes. The local coordination of $\mathrm{V}$ in residuum has also been determined by XAFS spectroscopy. Comparison of the EXAFS and XANES spectra of non-porphyrin $\mathrm{V}$ to that of reference compounds indicates that the non-porphyrin $\mathrm{V}$ exists in a vanadyl porphyrin environment. ${ }^{18,19}$ In vanadyl porphyrin, the V(IV) ion is displaced approximately $0.5 \AA$ above the plane of the four $\mathrm{N}$ ligands toward the axially bound oxygen atom. The $\mathrm{V}-\mathrm{N}$ distance by XRD is 2.102 $\AA$, and the $V-O$ distance is $1.620 \AA .{ }^{28}$ Since most of the $\checkmark$ in residuum asphaltene is non-porphyrin, the EXAFS $\mathrm{V}-\mathrm{N}(2.08 \AA)$ and $\mathrm{V}-\mathrm{O}(1.61 \AA)$ bond distances support the assignment that the $\mathrm{V}$ non-porphyrins have an identical coordination environment to vanadyl porphyrin. ${ }^{17}$ The results of this study are in agreement with previous EXAFS studies and indicate that the local structure of porphyrin and non-porphyrin $\mathrm{V}$ in Maya residuum are very similar.

Because of the low concentrations of $\mathrm{Ni}$ in residuum, the local structure of non-porphyrin $\mathrm{Ni}$ has not previously been reported. Comparison of the EXAFS and XANES spectra with that of Ni TPP suggests that like $\mathrm{V}$, non-porphyrin $\mathrm{Ni}$ exists in a porphyrin-type coordination. In nickel porphyrin, the $\mathrm{Ni}(\mathrm{II})$ ion is located (by XRD) at the center of the porphyrin ring at a distance of $1.960 \AA$ from each of four $\mathrm{N}$ ligands. ${ }^{29}$ In Ni porphyrin, the steric constraints of the porphyrin ring lead to

(30) Reynolds, J . G.; Biggs, W. R. Acc. Chem. Res. 1988, 21 (9), 319. (31) Reynolds, J. G.; Biggs, W. R. Fuel Sci. Technol. Int. 1986, 4 (6), 779 .

(32) Malhotra, V. M.; Buckmaster, H. A. Fuel 1985, 64, 335. 
Table 5. Ni EXAFS Parameters of Model Fit

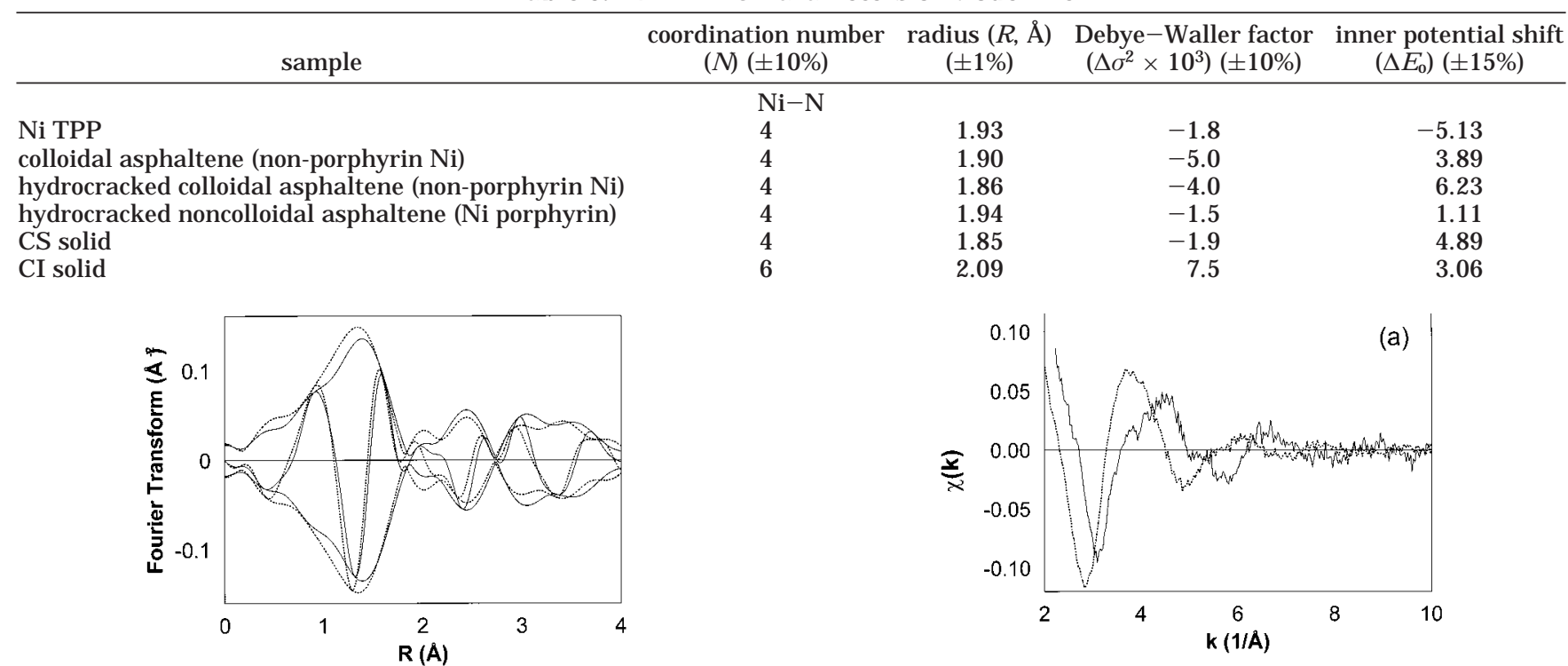

Figure 8. Fourier transform $\left(\mathrm{K}^{1}, \Delta \mathrm{k}=2.5-10 \AA^{-1}\right)$ of $\mathrm{Ni}$ EXAFS data for the CS solid (solid line) and Ni TPP reference (dotted line).

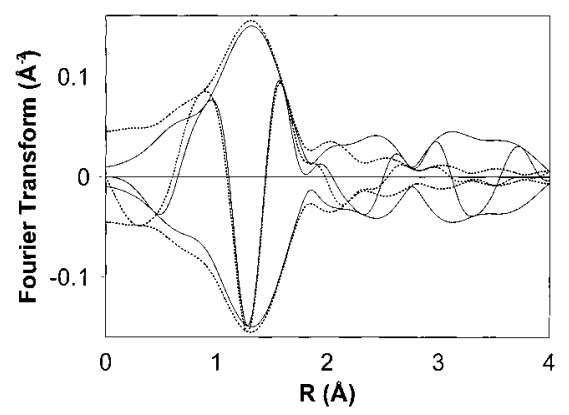

Figure 9. Fourier transform $\left(\mathrm{k}^{1}, \Delta \mathrm{k}=2.5-9 \AA^{-1}\right)$ of $\mathrm{Ni}$ EXAFS data for the CS solid, raw data (solid line) and model fit (dotted line).

a $\mathrm{Ni}-\mathrm{N}$ bond distance which is approximately $0.1 \AA$ longer than that in normal diamagnetic square-planar $\mathrm{Ni}$ (II) compounds. ${ }^{33,34}$ Accurate determination of the $\mathrm{Ni}-\mathrm{N}$ bond distance, therefore, could distinguish between $\mathrm{Ni}$ in a (true) porphyrin coordination environment and $\mathrm{Ni}$ with a square-planar coordination of four $\mathrm{N}$. The non-porphyrin $\mathrm{Ni}-\mathrm{N}$ bond distance of $1.90 \AA$ is similar to that in Ni TPP (1.93 $\AA$ ), however, there is sufficient error in the EXAFS bond distance determination to make assignment of the porphyrin structure uncertain. While it is certain that non-porphyrin $\mathrm{Ni}$ exists in a square-planar coordination of four $\mathrm{N}$ ligands, a porphyrin coordination environment cannot be unambiguously established by XAFS spectroscopy.

After extensive cracking of the residuum hydrocarbons, the local structure of $\mathrm{Ni}$ and $\mathrm{V}$ remaining in the hydrocracked asphal tene is little changed, i.e., porphyrinic coordination. While the residuum conversion to lower boiling products was 57\%, the elemental composition, $C_{a}$, molecular weight, etc., indicates that the hydrocracked asphaltenes are smaller and more aromatic than the residuum asphaltenes (compare Tables 1 and 2). ${ }^{20}$ Similar results have previously been re-

(33) Lingafelter, E. C.; Braun, R. L. J . Am. Chem. Soc. 1966, 88, 2951.

(34) Dobler, M.; Dunitz, J . D. Helv. Chim. Acta 1971, 54, 90.
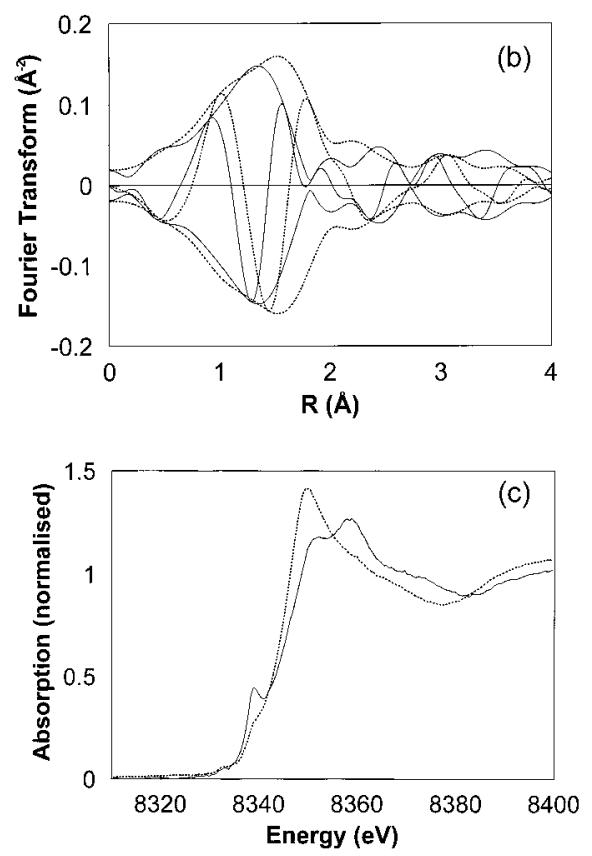

Figure 10. Ni XAFS spectra for $\mathrm{CS}$ (solid line) and $\mathrm{Cl}$ (dotted line) sol id. (a) Raw EXAFS data. (b) Fourier transform $\left(\mathrm{k}^{1}, \Delta \mathrm{k}\right.$ $\left.=2.5-9 \AA^{-1}\right)$. (c) Near edge.

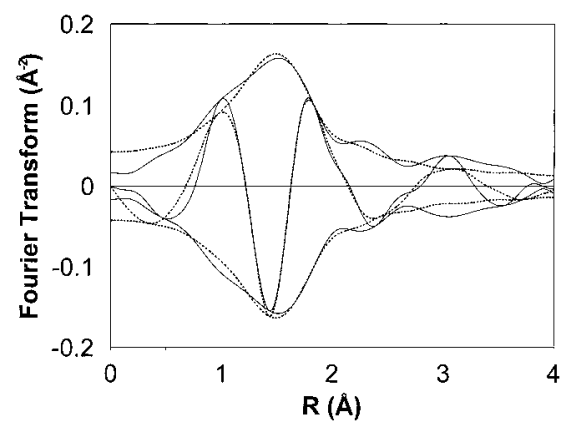

Figure 11. Fourier transform $\left(\mathrm{k}^{1}, \Delta \mathrm{k}=2.5-9 \AA^{-1}\right)$ of $\mathrm{Ni}$ EXAFS data for the $\mathrm{Cl}$ solid, raw data (solid line), and model fit (dotted line).

ported. ${ }^{27}$ In addition to thermal cracking, the function of the Mo catalyst is to hydrogenate the hydrocracked radical and ol efin intermediates. ${ }^{35}$ Although the activity 
of the Mo catalyst is not high compared, for example, to a typical $\mathrm{NiMo/alumina}$ catalyst, there is about $40 \%$ desulfurization of the residuum. This corresponds to ca. $2.5 \mathrm{wt} \%$ of the feed converted to $\mathrm{H}_{2} \mathrm{~S}$, a large excess compared to the amount of metal. Nevertheless, $\mathrm{Ni}$ and $V$ sulfides are not formed. Rather, the local structure of hydrocracked $\mathrm{Ni}$ and $\mathrm{V}$ are identical to those in residuum. The similar thermal and chemical stability of non-porphyrin $\mathrm{Ni}$ and $\mathrm{V}$ to that of petroporphyrins suggests a similar structure.

During hydrocracking, approximately $1 \%$ of the residuum separates from the oil as a toluene-insoluble solid. About $30 \%$ of the $\mathrm{TI}$ solid is slightly soluble in chlorobenzene, indicating that this fraction is molecular. Within this CS fraction, the coordination geometries of $\mathrm{Ni}$ and $\mathrm{V}$ are very similar to those in porphyrins. The lower solubility of these metals, however, indicates that the porphyrin ring has undergone hydrocracking reactions, likely thermal dealkylation. Aromatic dealkylation would increase the $C_{a}$ and decrease the metal solubility but leave the local $\mathrm{Ni}$ and $\mathrm{V}$ coordination unchanged. The similarity of the coordination geometry of the metals in the CS solid with those in residuum is consistent with the high thermal stability of the porphyrin ligand coordination.

While the local coordination of about $10 \%$ of the $\mathrm{Ni}$ and $\mathrm{V}$ in $\mathrm{TI}$ solid was similar to that of the metal compounds in the residuum, the majority of $\mathrm{Ni}$ and $\mathrm{V}$ was present in an octahedral coordination of $\mathrm{N}$ and/or $\mathrm{O}$ ligands. Coordination complexes of transition-metal porphyrins are known in which one $\mathrm{N}$ ligand, for example, may be added to the coordination sphere of metal ion, ${ }^{29}$ however, addition of two ligands resulting in octahedral coordination is highly unusual and not known for $\mathrm{Ni}$ or $\mathrm{V}$. Furthermore, since the $\mathrm{V}(\mathrm{IV})$ ion is located $0.5 \AA$ above the plane of the porphyrin ring, steric repulsion from the porphyrin ring makes coordination of a sixth ligand highly unlikely. Octahedral coordination of $\mathrm{Ni}$ and $\mathrm{V}$, therefore, suggests that the porphyrin ring has undergone extensive reaction. While it is unclear exactly what ligands are coordinated to the $\mathrm{Ni}$ and $\mathrm{V}$ or what reactions have occurred to the porphyrin ring, it is clear that the local structure of $\mathrm{Ni}$ and $\mathrm{V}$ in the $\mathrm{Cl}$ solid is significantly different from the porphyrin coordination geometry. While there has been a significant change in the coordination geometry, the metals still appear to be coordinated to the same atoms in the porphyrin compound, i.e., $\mathrm{N}$ and $\mathrm{O}$. All the XAFS

(35) Miki, Y.; Yamadaya, S.; Oba, M.; Sugimoto, Y. J . Catal. 1983, 83, 371. results demonstrate that metal-ligand coordinations in the porphyrin structure are very strong.

In summary, the XAFS structural analysis and chemical reactivity indicate that all $\mathrm{Ni}$ and $\mathrm{V}$ in Maya residuum is present as a porphyrin-type coordination complex. Furthermore, this coordination environment is highly stable and severe reaction conditions are required for decomposition of these metal compounds. Because of this stability, it appears unlikely that a simple chemical treatment or procedure of residuum can be devel oped which will affect demetalation. Under the severe reaction conditions required for metals removal, one can also expect extensive reaction of the residuum hydrocarbons.

\section{Conclusion}

Although porphyrin and non-porphyrin $\mathrm{Ni}$ and $\mathrm{V}$ display different UV-vis spectra, XAFS spectroscopy indicates that the local structure, coordination geometry, and bond distances are similar. In addition, porphyrin and non-porphyrin $\mathrm{Ni}$ and $\mathrm{V}$ have similar thermal and chemical stabilities, which is also consistent with the proposal that they have closely related structures.

After hydrocracking residuum to about $60 \%$ conversion, the local coordination of the $\mathrm{Ni}$ and $\mathrm{V}$ in hydrocracked asphaltenes is little changed. Because of the stability of the porphyrin coordination, severe reaction conditions are required to decompose the $\mathrm{Ni}$ and $\mathrm{V}$ complexes in residuum. Under such reaction conditions, however, metals removal is accompanied by extensive hydrocarbon reactions and the formation of solid. Approximately $10 \%$ of the $\mathrm{Ni}$ and $\mathrm{V}$ in this solid is still present in a porphyrin-type coordination. The remainder of the metals in the solid have an octahedral coordination, indicating decomposition or reaction of the porphyrin ring. The metals, however, remain coordinated to $\mathrm{N}$ and $\mathrm{O}$ ligands. Even after extensive hydrocracking of the residuum under high pressures of hydrogen and in the presence of a large excess of $\mathrm{H}_{2} \mathrm{~S}, \mathrm{Ni}$ and $\mathrm{V}$ sulfides are not formed.

Acknowledgment. This work was partially supported by a CRADA agreement between Amoco Corp. and Argonne National Laboratory through the DOEBartlesville F ossil E nergy Project, U.S. Department of Energy, under Contract No. W-31-109-ENG-38. The authors also thank station scientists Fred Mosselmans (Daresbury, U.K.) and Andiano Philiponi (ESRF, France) for their technical assistance.

EF 9802328 